\title{
Validation of the Emotiv EPOC EEG system for research quality auditory event-related potentials in children
}

Nicholas A Badcock, Kathryn A Preece, Bianca de Wit, Katharine Glenn, Nora Fieder, Johnson Thie, Genevieve McArthur

Background. Previous work has demonstrated that a commercial gaming electroencephalography (EEG) system, Emotiv EPOC, can be adjusted to provide valid auditory event-related potentials (ERPs) in adults that are comparable to ERPs recorded by a research-grade EEG system, Neuroscan. The aim of the current study was to determine if the same was true for children.Method. An adapted Emotiv EPOC system and Neuroscan system were used to make simultaneous EEG recordings in nineteen 6- to 12-year-old children under "passive" and "active" listening conditions. In the passive condition, children were instructed to watch a silent DVD and ignore 566 standard $(1000 \mathrm{~Hz})$ and 100 deviant $(1200 \mathrm{~Hz})$ tones. In the active condition, they listened to the same stimuli, and were asked to count the number of 'high' (i.e. deviant) tones.Results. Intraclass correlations (ICCS) indicated that the ERP morphology recorded with the two systems was very similar for the P1, N1, P2, N2, and P3 ERP peaks ( $r=.82$ to .95) in both passive and active conditions, and less so, though still strong, for mismatch negativity ERP component (MMN; $r=.67$ to .74). There were few differences between peak amplitude and latency estimates for the two systems.Conclusions. An adapted EPOC EEG system can be used to index children's late auditory ERP peaks (i.e. P1, N1, P2, N2, P3) and their MMN ERP component. 
2 Nicholas A Badcock ${ }^{1,2}$, Kathryn A Preece ${ }^{1,2}$, Bianca de $\mathrm{Wit}^{2,1}$, Katharine Glenn ${ }^{3}$, Nora Fieder ${ }^{2,1}$,

3 Johnson Thie ${ }^{4}$, and Genevieve McArthur ${ }^{2,1}$

4

$5{ }^{1}$ ARC Centre of Excellence in Cognition and its Disorders, Macquarie University, North Ryde, NSW,

6 Australia

$7 \quad 2$ Department of Cognitive Science, Macquarie University, North Ryde, NSW, Australia

$8 \quad{ }^{3}$ MultiLit, 3/75 Talavera Rd, Macquarie Park NSW 2113

$9{ }^{4}$ School of Electrical and Information Engineering, University of Sydney, Sydney, NSW, Australia

10

11 Note: Nicholas A Badcock and Kathryn A Preece are joint first authors for this work

12 Corresponding Author:

13 Nicholas A Badcock

14 ARC Centre of Excellence in Cognition and its Disorders,

15 Department of Cognitive Science,

16 Macquarie University, Sydney, NSW,

17 Australia

18 Telephone: + 61298504067

19 e-mail: nicholas.badcock@mq.edu.au 
Introduction

21 An auditory event-related potential (ERP) is the average pattern of electrical activity generated by

22 neurons in response to a particular auditory event. Auditory ERPs can be measured without a listener's

23 overt attention. Such "passive" auditory ERPs are a useful means of investigating the role of auditory

24 processing in people who find it difficult to pay attention to stimuli, to make decisions about stimuli, or

25 plan overt responses to stimuli. Thus, passive auditory ERPs have proved useful for investigating

26 auditory processing in attention deficit hyperactivity disorder (ADHD; Taylor et al., 1997),

27 schizophrenia (Todd, Michie \& Jablensky, 2003); autism (McPartland et al., 2004); developmental

28 dyslexia (McArthur, Atkinson \& Ellis, 2009); and specific language impairment (Whitehouse, Barry \&

29 Bishop, 2008).

A limitation of passive auditory ERPs is that they are typically measured using research-grade

31 equipment housed in a laboratory. Such settings can be intimidating for many people, particularly

32 children and adults with cognitive disorders. Fortunately, recent research has shown that a commercial

33 "gaming" electroencephalography (EEG) system, called "EPOC" by Emotiv (www.emotiv.com), can

34 be adapted to produce valid ERPs. Badcock et al. (2013) examined auditory ERPs in "passive"

35 (standard and deviant tones are ignored) and "active" (deviant tones are counted) listening conditions

36 in adults, using an adapted EPOC system and a research-grade Neuroscan system. They found high

37 reliability for the "late auditory ERP" peaks (i.e. P1, N1, P2, N2, and P3) but not for the "mismatch

38 negativity" component (MMN; see Näätänen et al., 2004). The EPOC system has also been

39 successfully used to measure the auditory P3 response (Debener et al., 2012; De Vos, Gandras \&

40 Debener, 2014) and the visual P3 response (Duvinage et al., 2013; De Vos et al., 2014). Considered

41 together, the outcomes of these seminal studies suggest that the EPOC system can be adapted to record

42 valid auditory P1, N1, P2, N2, and P3 ERP peaks in adults. 
To our knowledge, no study has yet tested if an adapted EPOC system can produce valid auditory

44 ERPs in children. This cannot be inferred from previous validation studies done with adults because

45 children have (1) different ERPs to adults due to cortical and cognitive immaturity (Ponton et al., 2002;

46 Coch, Sanders \& Neville, 2005; Mahajan \& McArthur, 2012, 2013); (2) “noisier” ERPs than adults

47 (Coch \& Gullick, 2012); and (3) more difficultly keeping still during long test sessions than adults, so

48 their EEG (and ERP) responses may be contaminated to a greater degree by electrical noise generated

49 by movement. The aim of the current study was to test the validity of children's passive and active

50 auditory ERPs measured via an adapted EPOC system. In line with an analogous adult study (i.e.

51 Badcock et al., 2013) we predicted that the adapted EPOC system would produce valid ERPs for the

52 highly reliable late auditory ERP peaks (P1, N1, P2, P2, P3) but invalid ERPs for the less reliable

53 MMN component.

\section{Materials and Methods}

55 The Macquarie University Human Research Ethics Committee approved the methods used in this study 56 (approval number: 5201200658).

\section{Participants}

58 Participants were twenty-one children (11 females, 10 males) aged between 6 and 12 years $(\mathrm{M}=9.23$,

$59 \mathrm{SD}=1.80)$. Parents or guardians of the children provided written informed consent for their child's

60 participation (see Supplementary materials for information-consent form), and children were

61 reimbursed $\$ 15$ for their time. Participants were required to have normal hearing and vision, and no

62 history of epilepsy. One child was excluded from the study due to a reported hearing loss; another child

63 was excluded because the EPOC event-markers failed to record; and a third was excluded due to a

64 condition coding error. Therefore the final sample included 18 children. Based on our previous 
65 research demonstrating a large effect size (0.7, Badcock et al., 2013), G*Power (Faul et al., 2007,

66 2009) estimated that a sample size of 11 would provide adequate power for this experiment $(0.8)$.

\section{Stimuli}

68 Presentation (Version 16; Neurobehavioural Systems) was used to deliver tones in passive and active

69 conditions (see below) at a volume that was comfortable for each participant (note: the volume

70 remained fixed across conditions). Each condition consisted of 566, 175-ms, 1000-Hz standard tones

71 (10-ms rise and fall time; $85 \%$ of trials) and 100, 175-ms, $1200-\mathrm{Hz}$ deviant tones (10-ms rise and fall

72 time; $15 \%$ of trials). Deviant tones were presented after 3 to 35 (randomly allocated) standard tones.

73 The stimulus onset asynchrony was jittered between 900 and $1100 \mathrm{~ms}$ to minimize EEG activity related

74 to anticipatory processes. Tones were presented binaurally via Phillips SHS4700/37ear clip

75 headphones fixed to the EPOC headset.

76 In the passive condition, participants were instructed to watch a silent movie and ignore the tones

77 presented through the headphones. In the active condition, participants were instructed to count the

78 "high" tones whilst watching the silent movie. Participants were asked, and reminded where necessary,

79 to stay as still as possible. Each condition lasted approximately 13 minutes, separated by a short-break.

\section{Neuroscan system}

81 The research-grade EEG system (Neuroscan Version 4.3; widely accepted for psychophysiological 82 research) used an EEG electrode cap (EasyCap) fitted with $14 \mathrm{Ag}-\mathrm{AgCl}$ electrodes located at F3, F7, 83 FC4, FT7, T7, P7, P8, T8, FT8, FC4, F8, F4, M1 (online reference), and M2. Electrodes placed above 84 and below the left eye measured vertical eye movements ("VEOG"), and electrodes placed on the outer 85 side of each eye measured horizontal eye movements ("HEOG"). Please note that the M2 (right 86 mastoid), VEOG, and HEOG electrodes were set up as per standard procedures even though these 
87 electrodes were not used in the analysis as EPOC does not provide equivalent measurements. The 88 ground electrode was positioned between FPz and Fz.

Neuroscan was recorded at $1000 \mathrm{~Hz}$. Triggers were inserted into the EEG to indicate the onset of

90 each stimulus. These triggers were generated by Presentation, and were inserted into the EEG via a

91 parallel port.

\section{Adapted EPOC system}

93 The EPOC system used a wireless headset with flexible plastic arms that held gold-plated sensors

94 against the head at 16 sites that aligned with the research EEG headset: AF3, F7, F3, FC5, T7, P7, O1,

$95 \mathrm{O} 2, \mathrm{P} 8, \mathrm{~T} 8, \mathrm{FC} 6, \mathrm{~F} 4, \mathrm{~F} 8, \mathrm{AF} 4, \mathrm{M} 1$ and M2. M1 acted as a ground reference point for measuring the

96 voltage of the other sensors. M2 acted as a feed-forward reference point for reducing electrical

97 interference from external sources. The remaining signals were high-pass filtered with a $0.16 \mathrm{~Hz}$ cut-off, pre-

98 amplified and low-pass filtered at an $83 \mathrm{~Hz}$ cut-off. The analogue signals were then digitised at $2048 \mathrm{~Hz}$, filtered

99 using a 5th-order sinc notch filter $(50-60 \mathrm{~Hz})$, and low-pass filtered before being down-sampled to $128 \mathrm{~Hz}$

100 (specifications taken from the gaming EEG system web forum). The effective bandwidth was $0.16-43 \mathrm{~Hz}$.

101 EPOC was recorded at $128 \mathrm{~Hz}$.

The EPOC system was adapted to accurately time-lock the EEG signal to the onset of each

103 stimulus by marking the EEG signal with an electrical pulse triggered by a wireless transmission

104 system (Thie, 2013). The system consisted of transmitter and receiver units that were linked using

105 infrared (IR) light. The transmitter unit was attached to the audio output of the stimulus presentation

106 computer. The receiver unit was mounted in close proximity to the participant (i.e. taped to their

107 shoulder or resting on a table) with its output wires attached to two of the EEG electrodes (O1 and $\mathrm{O} 2)$.

108 These electrodes were attached directly to the Driven Right Leg (DRL) through wires and 4700-ohm

109 resistors that mimicked a perfect connection with the scalp. The transmitter unit was made up of a 
110 microcontroller board (Arduino Uno) and an interface board. This board amplified the audio stimuli

111 and fed it to the Arduino's analogue input. The receiver waited for a number from the transmitter to

112 trigger a 100-ms-wide pulse. There was a 19-ms delay (accounted for the trigger processing) between

113 the onset of the stimulus and the onset of the marker pulse due to the buffering of the audio signal in

114 order to determine its frequency and the transmission of the 8-bit number.

\section{Procedure}

116 Neuroscan was setup first and adjusted until sensor impedance was below $5 \mathrm{kOhms}$. The EPOC

117 headset was fitted over the EasyCap (for a detailed description, see Badcock et al., 2013). This allowed

118 for simultaneous measurements of EEG by the Neuroscan and EPOC systems (see Fig. 1; for electrode

119 locations see Fig 2). EPOC electrode connectivity was tested using the TestBench software. Sensors

120 were adjusted until connectivity reached the "green" level, which represented impendences less than

$121220 \mathrm{kOhms}$ (measured using a resistor between an electrode and the DRL, M2 in the current setup).

122 The total setup time was approximately 55 minutes.

Insert Figures 1 and 2 about here

\section{Offline EEG processing}

125 Both Neuroscan and EPOC EEG recordings were processed in the same way using EEGLAB version

126 11.0.4.3b (Delorme \& Makeig, 2004). Large artefacts in each EEG were first excluded by eye. The

127 Neuroscan EEG data were then downsampled to $128 \mathrm{~Hz}$ in order to match the sampling rate of the

128 EPOC system. The EEG data were then bandpass filtered from 0.1 to $30 \mathrm{~Hz}$, separated into epochs that

129 started -102 ms before the onset of each tone and ended $500 \mathrm{~ms}$ after the onset of each tone, and

130 baseline corrected between -102 and $0 \mathrm{~ms}$. Any epochs with an amplitude in excess of $+/-150 \mu \mathrm{V}$ were

131 excluded. 
133 (note: channels capturing the eye-movements for Neuroscan were not included in this process to

134 maintain equivalent processing between the systems). This process did not identify eye-blink related

135 components in any of the datasets. Therefore eye-blinks were either not consistent or strong enough to 136 meaningfully affect the data.

In order to best compare the two systems, only those epochs accepted for both EEG systems (i.e.

138 shared epochs) were included in the analysis (we thank Phillip Ruhnau for this suggestion). For each

139 child, the shared epochs were averaged together to produce late auditory ERP waveforms that

140 comprised P1, N1, P2, and N2 peaks for the standard and deviant tones, in the passive and active

141 conditions. Shared epochs to standard and deviant tones in the passive condition were averaged

142 separately and then subtracted (i.e. the ERP to standard tones was subtracted from the ERP to deviant

143 tones) to produce a mismatch negativity (MMN) waveform.

\section{Analysis}

145 In line with the previous EPOC validation study done with adults, the analysis focused on data from

146 frontal sites in the left and right hemispheres: F3 and F4 for Neuroscan, and AF3 and AF4 for EPOC.

The ERPs produced by the two systems were compared in three ways: (1) total number of

148 accepted epochs were used to compare the quality of the Neuroscan and EPOC EEG data, (2) intraclass

149 correlations (ICCs, for details see McArthur \& Bishop, 2004; Bishop et al., 2007) were used to index

150 the similarity of Neuroscan and EPOC waveforms (between -102 to $500 \mathrm{~ms}$ ), and (3) peak amplitude

151 and latency measures were used to compare the size and timing of each ERP peak or component. The

152 number of epochs and peak comparison data sets were tested for normality (Shapiro-Wilk) and equal

153 variance (F test). Single- and paired-sample t-tests and Wilcoxon-signed ranks were used to evaluate 
154 the statistical reliability between EEGs systems comparisons, and Cohen's d was used to evaluate the 155 magnitude of the effects. We used a criteria of $\mathrm{p}<.05$ unless otherwise specified.

156 Regarding the size and timing of ERP peaks and components, peak amplitude and latency

157 measures were initially calculated using an automated procedure that identified the point of maximum 158 amplitude (positive or negative) within appropriate time intervals or "search windows". These intervals

159 were determined by visual inspection of the relevant grand mean ERP waveforms (as described by

160 Hoormann et al., 1998), and were as follows: 50 to $140 \mathrm{~ms}$ (P1); 70 to 140 (N1); 140 to $200 \mathrm{~ms}$ (P2);

161260 to $400 \mathrm{~ms}$ (N2); 260 to $400 \mathrm{~ms}$ (P3); 140 to 260 (MMN). We then checked the validity of each

162 peak measure for each child by visually inspecting individual waveforms. This revealed that the N1

163 and P2 peaks were missing in 11 to 14 (60 to 77\%) children across all conditions, which is

164 characteristic of children's auditory ERPs (Ponton et al., 2000; Mahajan \& McArthur, 2012, 2013).

165 Invalid data points for missing peaks were deleted from the dataset. A further $15 \%$ of the measures

166 produced by the automated peak detection were invalid, identifying an end-point of the range greater in

167 magnitude that the true peak. Invalid end-point measures were corrected manually to ensure all peak

168 amplitude and latency measures for all children were valid.

169 Results

170 Number of accepted epochs

171 The distributions for the number of accepted epochs were negatively skewed, thus, Wilcoxon Signed

172 Rank Tests were used to compare the data recorded by the two systems. The median number of

173 accepted epochs, inter-quartile range, and Wilcoxon signed ranks statistics are presented in Table 1.

174 There were statistically fewer acceptable epochs for EPOC than Neuroscan in all conditions.

175 Nevertheless, the number of accepted epochs for both the EPOC and Neuroscan systems was more

176 than adequate for waveform generation for all participants. 
Insert Table 1 about here

\section{ICCs}

\section{P1, N1, P2, and N2}

180 The mean of the group ERP waveforms produced by the Neuroscan and EPOC systems to the standard

181 and deviant tones in the passive and active conditions are displayed in Fig 3 (see Supplementary Figs 1

182 and 2 for the auditory ERPs of individual children). The ICCs between late auditory ERP waveforms

183 generated by the two systems to standard and deviant tones in the passive and active conditions are

184 presented in Table 2 . The range of ICCs for the standard tones was 0.91 to 0.95 and for the deviant

185 tones was 0.82 to 0.86 . All of these distributions were negatively skewed; therefore, statistical

186 differences to zero were assessed using single-sample Wilcoxon signed ranks, all of which were

187 significant: all $\mathrm{Z}=4.48, \mathrm{p}<.001$. These results indicate a strong correspondence between the

188 measurements made with the two systems.

191 The mean of the group late auditory ERP waveforms produced by the Neuroscan and EPOC systems to

192 the deviant tones in the active condition are displayed in Fig 3 (see Supplementary Fig 2 for the

193 auditory ERPs of individual children). The corresponding ICC values are shown in Table 2. The ICCs

194 for F3/AF3 and F4/AF4 were 0.85 and 0.83 respectively, and the negatively skewed distributions were

195 significantly different to zero: both single-sample Wilcoxon signed ranks, $Z=4.48, p<.001$. These

196 results indicate a strong correspondence between the measurements made with the two systems. 


\section{MMN}

198 The mean of the group MMN ERP waveforms produced by the Neuroscan and EPOC systems are 199 presented in Fig 4 (see Supplementary Fig 3 for the MMN ERP waveforms of individual children). The 200 ICCs between the MMN waveforms generated by the Neuroscan and EPOC systems are shown in 201 Table 4. These ICCs were: 0.74 for F3/AF3, and 0.67 for F4/AF4. Both distributions were normally 202 distributed and single-sample t-tests determined the ICCs were statistically different to zero; F3/AF4, $203 \mathrm{t}(17)=15.28, \mathrm{p}<.001 ; \mathrm{F} 4 / \mathrm{AF} 4, \mathrm{t}(17)=12.02, \mathrm{p}<.001$. These results indicate a moderate to strong 204 correspondence for the MMN waveforms between the measurements made with the two systems. Insert Figure 4 and Table 4 about here

\section{Peak amplitude and latency}

The descriptive statistics for P1, N1, P2, N2, P3 and MMN peak amplitude and latency measures produced by the Neuroscan and EPOC systems for standard and deviant tones in the passive and active conditions at F3/AF4 and F4/AF4 are reported in Tables 3, 4, and 5. Peak comparisons between the two systems were conducted using paired-samples t-tests and Wilcoxon singed rank tests, depending upon the normality of the data as indicated in the tables. Due to multiple comparisons, statistical tests with $\mathrm{p}$-values less than .01 will be highlighted ( $\mathrm{p}<.05$ and .001 are also indicated in the tables).

\section{P1, N1, P2, and N2}

215 For the P1, N1, P2, and N2 late auditory ERP peaks, there were 18 comparisons that differed 216 statistically between the two systems. Two of the differences reflected reduced N2 amplitude in the 217 EPOC system: differences of .99 and $.93 \mu$ Vs in the passive and active conditions respectively, both 218 small in magnitude ( $\mathrm{d}=0.29$ and .30$)$. Sixteen of the differences reflected a delay in the latency of the 
219 peaks measured by the EPOC system and 9 of these were evident to the standard tone. The average

220 delay for these comparisons was $8 . .88 \mathrm{~ms}(\mathrm{SD}=2.45)$ and effect sizes were small to large $(\mathrm{d}=0.29$ to

221 1.09).

$222 \quad \mathbf{P 3}$

223 The differences in P3 amplitude between the systems were non-significant and small $(\mathrm{d}<0.05)$. The

$224 \mathrm{P} 3$ produced by the $\mathrm{EPOC}$ system at $\mathrm{F} 3 / \mathrm{AF} 3$ was significantly later than that produced by the

225 Neuroscan system by 15 ms (see Table 5). Cohen's $d$ effects sizes were moderate ( $(d=044$ and 0.45 ).

226 MMN

227 The differences in MMN amplitude and latency between the two systems were non-significant and $228 \operatorname{small}(\mathrm{d}<0.03)$.

\section{Discussion}

230 The aim of the current study was to assess the validity of the Emotiv EPOC gaming EEG system as an

231 auditory ERP measurement tool in children. To this end, we simultaneously measured ERPs using a

232 research-grade Neuroscan system and the EPOC system in children aged between 6 and 12 years.

233 Children were presented with standard and deviant tones in both passive (ignore tones) and active

234 (count high tones) listening conditions. There are three key findings. First, whilst both EEG systems

235 recorded a high proportion of accepted epochs, fewer were acceptable for EPOC. This was also found

236 by Badcock et al. (2013) when they tested adults. Fewer acceptable epochs with EPOC may stem from

237 reduced stability of EPOC's saline-soaked cotton sensors resting on the scalp, relative to the gel used

238 with Neuroscan, which effectively glues to sensor the scalp with gel. Having said this, EPOC recorded

239 adequate numbers of acceptable epochs to produce reliability later auditory ERPs. 
Second, the systems produced similar late auditory ERP (ICCs: 0.82-0.95) and MMN

241 waveforms (ICCs: 0.60-0.77). These ICCs are higher than those previously reported by Badcock et al.

242 (2013) who found that ICCs in adults for the late auditory ERPs ranged from 0.57 to 0.80, and that the

243 ICC for the MMN was 0.44. Apart from differences in populations studied (i.e. children versus adults),

244 there are three major differences between the current and the previous study that may explain the

245 different ICCs. First, the current study was conducted within a shielded room, whereas the previous

246 study was not. It is conceivable that the shielded room resulted in cleaner EEG recordings. Second, the

247 analysis for the current study used only overlapping epochs that were accepted by both EEG systems.

248 However, the previous study rejected fewer epochs, which would have resulted in a high proportion of

249 overlapping epochs. Thus, this seems an unlikely explanation of the higher ICCs in the current study.

250 Third, the current study used a wireless triggering system for the EPOC system, while the previous

251 study used a wired system. In the previous study, we noted that participant movement with the wired

252 system caused interference to the EEG signal. However, fewer epochs were rejected in the previous

253 study so this too seems an unlikely explanation for the higher ICCs in the current study. It therefore

254 seems most likely that the shielded room produced the higher ICCs in the current study compared to

255 the previous study done with adults by Badcock et al.

Third, there were only a few differences between the peak amplitude and latency measures

257 produced by the EPOC and Neuroscan systems, which mostly related to delayed latencies for the

258 EPOC system (i.e. an average delay was $8.1 \mathrm{~ms}(\mathrm{SD}=5.92)$. This represents a single sample at $128 \mathrm{~Hz}$.

259 Since this delay was small, and occurred in a minority of comparisons, we do not believe it

260 significantly compromises the use of the EPOC system as a measure of auditory P1, N1, P2, N2, or P3

261 ERPs in children. 
262 Overall, the findings of the present study paired with Badcock et al. (2013) suggest that EPOC

263 compares well with Neuroscan for investigating late auditory ERPs in children. This opens up new

264 opportunities for conducting ERP studies with children with or without cognitive impairments who

265 find the laboratory settings associated with traditional research-grade EEG systems threatening or

266 uncomfortable. It also paves the way for large-scale studies of the development of typical and atypical

267 ERPs since it allows the measurement of children's ERPs in settings such as schools, childcare centres, 268 hospitals, and private clinical practices.

\section{Acknowledgements}

270 We would like to thank the participants and their parents who volunteered their time. 


\section{References}

272 Badcock NA, Mousikou P, Mahajan Y, de Lissa P, Thie J, McArthur G. 2013. Validation of the Emotiv EPOC® EEG gaming system for measuring research quality auditory ERPs. PeerJ 1:e38.

275

276

277

278

279

280

281

282

283 284

285

286

287

288 289 ERP: step function changes at start and end of adolescence. Developmental Science 10:565575.

Coch D, Gullick MM. 2012. Event-related potentials and development. In: Luck SJ, Kappenman ES eds. The Oxford handbook of event-related potential components. New York: Oxford University Press, 475-511.

Coch D, Sanders LD, Neville HJ. 2005. An Event-related Potential Study of Selective Auditory Attention in Children and Adults. Journal of Cognitive Neuroscience 17:605-622.

Debener S, Minow F, Emkes R, Gandras K, de Vos M. 2012. How about taking a low-cost, small, and wireless EEG for a walk? Psychophysiology 49:1617-1621.

Delorme A, Makeig S. 2004. EEGLAB: an open source toolbox for analysis of single-trial EEG dynamics including independent component analysis. Journal of Neuroscience Methods 134:921.

Duvinage M, Castermans T, Petieau M, Hoellinger T, Cheron G, Dutoit T. 2013. Performance of the Emotiv Epoc headset for P300-based applications. BioMedical Engineering OnLine 12:56.

Faul F, Erdfelder E, Lang A-G, Buchner A. 2007. G*Power 3: A flexible statistical power analysis program for the social, behavioral, and biomedical sciences. Behavior Research Methods 39:175-191. 
293 Faul F, Erdfelder E, Buchner A, Lang A-G. 2009. Statistical power analyses using G*Power 3.1: Tests for correlation and regression analyses. Behavior Research Methods 41:1149-1160.

295 296

297

298

299

300 301

302 303

304 305 306 307 308 309 310 311 312 313

Hoormann J, Falkenstein M, Schwarzenau P, Hohnsbein J. 1998. Methods for the quantification and statistical testing of ERP differences across conditions. Behavior Research Methods, Instruments, \& Computers 30:103-109.

Mahajan Y, McArthur G. 2012. Maturation of auditory event-related potentials across adolescence. Hearing Research 294:82-94.

Mahajan Y, McArthur G. 2013. Maturation of the auditory t-complex brain response across adolescence. International Journal of Developmental Neuroscience 31:1-10.

McArthur G, Atkinson C, Ellis D. 2009. Atypical brain responses to sounds in children with specific language and reading impairments. Developmental Science 12:768-783.

McArthur GM, Bishop DVM. 2004. Which People with Specific Language Impairment have Auditory Processing Deficits? Cognitive Neuropsychology 21:79-94.

McPartland J, Dawson G, Webb SJ, Panagiotides H, Carver LJ. 2004. Event-related brain potentials reveal anomalies in temporal processing of faces in autism spectrum disorder. Journal of Child Psychology and Psychiatry 45:1235-1245.

Näätänen R, Pakarinen S, Rinne T, Takegata R. 2004. The mismatch negativity (MMN): towards the optimal paradigm. Clinical Neurophysiology 115:140-144.

Ponton CW, Eggermont JJ, Kwong B, Don M. 2000. Maturation of human central auditory system activity: evidence from multi-channel evoked potentials. Clinical Neurophysiology 111:220236. 
314 Ponton C, Eggermont JJ, Khosla D, Kwong B, Don M. 2002. Maturation of human central auditory 315 system activity: separating auditory evoked potentials by dipole source modeling. Clinical $316 \quad$ Neurophysiology 113:407-420.

317 Taylor MJ, Sunohara GA, Khan SC, Malone MA. 1997. Parallel and serial attentional processes in ADHD: ERP evidence. Developmental Neuropsychology 13:531-539.

319 Thie J. 2013. A wireless marker system to enable evoked potential recordings using a wireless EEG system (EPOC) and a portable computer. PeerJ PrePrints 1.

321 Todd J, Michie P., Jablensky A. 2003. Association between reduced duration mismatch negativity 322 (MMN) and raised temporal discrimination thresholds in schizophrenia. Clinical comparison to a traditional amplifier. Journal of Neural Engineering 11:036008. Neurophysiology 114:2061-2070.

De Vos M, Kroesen M, Emkes R, Debener S. 2014. P300 speller BCI with a mobile EEG system:

De Vos M, Gandras K, Debener S. 2014. Towards a truly mobile auditory brain-computer interface: Exploring the P300 to take away. International Journal of Psychophysiology 91:46-53.

Whitehouse AJO, Barry JG, Bishop DVM. 2008. Further defining the language impairment of autism: Is there a specific language impairment subtype? Journal of Communication Disorders 41:319336. 


\section{Table $\mathbf{1}_{\text {(on next page) }}$}

Median number of accepted and shared epochs for Neuroscan and EPOC by condition and tone type

Median (inter-quartile range) number of accepted epochs for the Neuroscan and EPOC systems and total number of epochs shared (i.e. accepted for both systems) between systems in each condition (passive and active) for each tone type (standard, deviant, and total). Wilcoxon Signed Rank Tests ( $Z$ ) were used to test the difference between systems. Note: $* p<.05, * * p<.01$ 
2

\begin{tabular}{lllllllll}
\hline \multirow{2}{*}{ Condition } & Tone & Neuroscan & EPOC & $Z$ & Shared Epochs \\
\hline \multirow{2}{*}{ Passive } & Standard & 558 & $(18)$ & 528 & $(36)$ & $3.70^{*}$ & 523 & $(38)$ \\
& Deviant & 98 & $(4)$ & 94 & $(8)$ & $3.39^{*}$ & 94 & $(9)$ \\
& Total & 656 & $(23)$ & 622 & $(37)$ & & 614 & $(39)$ \\
\hline \multirow{2}{*}{ Active } & Standard & 558 & $(18)$ & 518 & $(36)$ & $3.66^{*}$ & 517 & $(34)$ \\
& Deviant & 98 & $(3)$ & 92 & $(4)$ & $3.60^{*}$ & 92 & $(4)$ \\
& Total & 656 & $(22)$ & 610 & $(38)$ & & 608 & $(39)$ \\
\hline
\end{tabular}

3 
Table 2 (on next page)

Neuroscan versus EPOC ERP and MMN waveform Intraclass Correlations

Mean intraclass correlations (ICC) (with 95\% confidence intervals) between Neuroscan and EPOC late auditory P1, N1, P2, N2, and P3 ERPs and the MMN component at F3/AF3 and F4/AF4 to standard and deviant tones in both passive and active conditions. Single-sample Wilcoxon signed rank test $p$-values are represented. Note: all $p<.001$ 


\begin{tabular}{lllcll}
\hline Condition & Tone & \multicolumn{4}{c}{ Electrode } \\
& & \multicolumn{2}{c}{ F3/AF3 } & F4/AF4 \\
\hline Passive & Standard & 0.95 & {$[0.93,0.97]$} & 0.93 & {$[0.91,0.95]$} \\
& Deviant & 0.86 & {$[0.81,0.91]$} & 0.82 & {$[0.74,0.90]$} \\
& MMN & 0.74 & {$[0.65,0.83]$} & 0.67 & {$[0.56,0.78]$} \\
\hline Active & Standard & 0.94 & {$[0.92,0.96]$} & 0.91 & {$[0.88,0.94]$} \\
& Deviant & 0.85 & {$[0.79,0.91]$} & 0.83 & {$[0.77,0.89]$} \\
\hline
\end{tabular}

2 
Table 3(on next page)

Neuroscan versus EPOC ERP peak comparisons: Passive Listening

Descriptive (n, M [lower, upper 95\% confidence intervals]) and inferential (t or Z and Cohen's d) statistics for peak (P1, N1, P2, N2) amplitude ( $\mu \mathrm{V}$ ) and latency (ms) measures at sties F3/AF3 and F4/AF4 for Neuroscan versus EPOC in the passive condition. Note: ^ Wilcoxon Z, * $p<.05, * * p<.01, * * * p<.001$ 


\begin{tabular}{|c|c|c|c|c|c|c|c|c|}
\hline \multirow[b]{2}{*}{ Tone } & \multirow[b]{2}{*}{ ERP } & \multirow[b]{2}{*}{ Measure } & \multicolumn{6}{|c|}{ EEG System } \\
\hline & & & Electrode & $\mathrm{n}$ & Neuroscan & EPOC & stat. & $\mathrm{d}$ \\
\hline \multirow[t]{16}{*}{ Standard } & \multirow[t]{4}{*}{$\mathrm{P} 1$} & \multirow[t]{2}{*}{ Amplitude } & F3/AF3 & 18 & $3.44[2.3,4.6]$ & $3.36[2.1,4.6]$ & $-0.17^{\wedge}$ & 0.03 \\
\hline & & & $\mathrm{F} 4 / \mathrm{AF} 4$ & 18 & $3.66[2.7,4.6]$ & $3.39[2.3,4.5]$ & 1.12 & 0.13 \\
\hline & & \multirow[t]{2}{*}{ Latency } & F3/AF3 & 18 & $98[89,107]$ & $104[96,112]$ & $-3.39^{\wedge * * *}$ & 0.31 \\
\hline & & & $\mathrm{F} 4 / \mathrm{AF} 4$ & 18 & $99[90,108]$ & $104[95,113]$ & $-2.74^{\wedge * *}$ & 0.29 \\
\hline & \multirow[t]{4}{*}{ N1 } & \multirow[t]{2}{*}{ Amplitude } & F3/AF3 & 9 & $-0.83[-2.0,0.4]$ & $-1.00[-2.0,0.0]$ & 0.6 & 0.11 \\
\hline & & & $\mathrm{F} 4 / \mathrm{AF} 4$ & 9 & $-0.97[-1.9,-0.0]$ & $-1.10[-2.1,-0.1]$ & 0.52 & 0.09 \\
\hline & & \multirow[t]{2}{*}{ Latency } & F3/AF3 & 9 & $122[114,130]$ & $131[122,140]$ & $-3.77 * *$ & 0.81 \\
\hline & & & $\mathrm{F} 4 / \mathrm{AF} 4$ & 9 & $119[111,127]$ & $128[122,134]$ & $-5.54 * * *$ & 0.89 \\
\hline & \multirow[t]{4}{*}{$\mathrm{P} 2$} & \multirow[t]{2}{*}{ Amplitude } & $\mathrm{F} 3 / \mathrm{AF} 3$ & 9 & $1.34[-0.7,3.4]$ & $1.11[-0.6,2.8]$ & 0.64 & 0.09 \\
\hline & & & F4/AF4 & 9 & $1.83[-0.3,4.0]$ & $1.32[-0.3,2.9]$ & 1.06 & 0.19 \\
\hline & & \multirow[t]{2}{*}{ Latency } & $\mathrm{F} 3 / \mathrm{AF} 3$ & 9 & $152[144,160]$ & $162[154,170]$ & $-4.63 * *$ & 0.93 \\
\hline & & & F4/AF4 & 9 & $155[146,164]$ & $169[159,179]$ & $-4.06^{* *}$ & 1.09 \\
\hline & \multirow[t]{4}{*}{$\mathrm{N} 2$} & \multirow[t]{2}{*}{ Amplitude } & $\mathrm{F} 3 / \mathrm{AF} 3$ & 18 & $-9.32[-10.9,-7.7]$ & $-8.33[-10.0,-6.6]$ & $-3.59^{\wedge * * *}$ & 0.29 \\
\hline & & & $\mathrm{F} 4 / \mathrm{AF} 4$ & 18 & $-8.80[-10.6,-7.0]$ & $-8.65[-10.2,-7.1]$ & -0.49 & 0.04 \\
\hline & & \multirow[t]{2}{*}{ Latency } & $\mathrm{F} 3 / \mathrm{AF} 3$ & 18 & $268[258,278]$ & $276[266,286]$ & $-4.88 * * *$ & 0.41 \\
\hline & & & $\mathrm{F} 4 / \mathrm{AF} 4$ & 18 & $265[256,274]$ & $278[268,288]$ & $-4.03 * * *$ & 0.63 \\
\hline \multirow[t]{16}{*}{ Deviant } & \multirow[t]{4}{*}{$\mathrm{P} 1$} & \multirow[t]{2}{*}{ Amplitude } & F3/AF3 & 18 & $3.90[2.4,5.4]$ & $3.68[2.1,5.2]$ & $-0.55^{\wedge}$ & 0.07 \\
\hline & & & $\mathrm{F} 4 / \mathrm{AF} 4$ & 18 & $3.88[2.6,5.2]$ & $3.42[1.9,4.9]$ & $-1.07^{\wedge}$ & 0.16 \\
\hline & & \multirow[t]{2}{*}{ Latency } & F3/AF3 & 18 & $95[87,103]$ & $103[94,112]$ & $-3.59^{\wedge * * *}$ & 0.51 \\
\hline & & & F4/AF4 & 18 & $97[88,106]$ & $99[89,109]$ & -0.64 & 0.13 \\
\hline & \multirow[t]{4}{*}{ N1 } & \multirow[t]{2}{*}{ Amplitude } & F3/AF3 & 7 & $-2.01[-3.1,-0.9]$ & $-2.14[-3.4,-0.9]$ & 0.36 & 0.09 \\
\hline & & & $\mathrm{F} 4 / \mathrm{AF} 4$ & 7 & $-1.11[-2.5,0.3]$ & $-2.51[-3.9,-1.2]$ & $-1.6^{\wedge}$ & 0.86 \\
\hline & & \multirow[t]{2}{*}{ Latency } & F3/AF3 & 7 & $133[117,149]$ & $131[123,139]$ & 0.31 & 0.13 \\
\hline & & & $\mathrm{F} 4 / \mathrm{AF} 4$ & 7 & $125[115,135]$ & $124[104,144]$ & 0.1 & 0.05 \\
\hline & \multirow[t]{4}{*}{$\mathrm{P} 2$} & \multirow[t]{2}{*}{ Amplitude } & F3/AF3 & 7 & $1.75[-0.4,3.9]$ & $0.81[-0.8,2.4]$ & 0.95 & 0.41 \\
\hline & & & $\mathrm{F} 4 / \mathrm{AF} 4$ & 7 & $1.38[-1.5,4.3]$ & $1.27[-0.5,3.1]$ & 0.11 & 0.04 \\
\hline & & \multirow[t]{2}{*}{ Latency } & F3/AF3 & 7 & $160[148,172]$ & $167[155,179]$ & $-2.55^{\wedge *}$ & 0.52 \\
\hline & & & $\mathrm{F} 4 / \mathrm{AF} 4$ & 7 & $166[152,180]$ & $163[148,178]$ & 0.39 & 0.17 \\
\hline & \multirow[t]{4}{*}{$\mathrm{N} 2$} & Amplitude & $\mathrm{F} 3 / \mathrm{AF} 3$ & 18 & $-10.30[-12.3,-8.3]$ & $-9.57[-11.5,-7.6]$ & -1.69 & 0.18 \\
\hline & & & F4/AF4 & 18 & $-10.10[-11.8,-8.4]$ & $-9.87[-11.1,-8.6]$ & -0.49 & 0.07 \\
\hline & & Latency & $\mathrm{F} 3 / \mathrm{AF} 3$ & 18 & $227[215,239]$ & $237[225,249]$ & $-2.71^{\wedge * *}$ & 0.38 \\
\hline & & & $\mathrm{F} 4 / \mathrm{AF} 4$ & 18 & $227[215,239]$ & $235[225,245]$ & $-2.25^{\wedge *}$ & 0.33 \\
\hline
\end{tabular}


Table 4(on next page)

Neuroscan versus EPOC EEG system ERP peak comparisons: Active Listening

Descriptive (n, M [lower, upper 95\% confidence intervals]) and inferential (t or Z and Cohen's d) statistics for peak (P1, N1, P2, N2) amplitude ( $\mu \mathrm{V}$ ) and latency (ms) measure at sites F3/AF3 and F4/AF4 for Neuroscan versus EPOC in the active condition. Note: ^ Wilcoxon Z, * $p<.05, * * p<.01, * * * p<.001$ 


\begin{tabular}{|c|c|c|c|c|c|c|c|c|}
\hline \multirow[b]{2}{*}{ Tone } & \multirow[b]{2}{*}{ ERP } & \multirow[b]{2}{*}{ Measure } & \multicolumn{6}{|c|}{ EEG System } \\
\hline & & & Electrode & $\mathrm{n}$ & Neuroscan & EPOC & stat. & $\mathrm{d}$ \\
\hline \multirow[t]{16}{*}{ Standard } & \multirow[t]{4}{*}{ P1 } & \multirow[t]{2}{*}{ Amplitude } & $\mathrm{F} 3 / \mathrm{AF} 3$ & 18 & $3.15[2.3,4.0]$ & $3.33[2.2,4.5]$ & $-0.68^{\wedge}$ & 0.09 \\
\hline & & & F4/AF4 & 18 & $3.15[2.3,4.0]$ & $3.09[1.9,4.2]$ & $-0.6^{\wedge}$ & 0.03 \\
\hline & & \multirow[t]{2}{*}{ Latency } & $\mathrm{F} 3 / \mathrm{AF} 3$ & 18 & $96[88,104]$ & $102[96,108]$ & $-3.06^{\wedge * *}$ & 0.43 \\
\hline & & & F4/AF4 & 18 & $94[86,102]$ & $104[97,111]$ & $-3.58^{\wedge * * *}$ & 0.6 \\
\hline & \multirow[t]{4}{*}{ N1 } & \multirow[t]{2}{*}{ Amplitude } & $\mathrm{F} 3 / \mathrm{AF} 3$ & 5 & $-1.72[-3.0,-0.4]$ & $-1.89[-3.2,-0.6]$ & 1.09 & 0.14 \\
\hline & & & F4/AF4 & 5 & $-1.72[-3.1,-0.4]$ & $-2.24[-3.8,-0.7]$ & 2.43 & 0.38 \\
\hline & & \multirow[t]{2}{*}{ Latency } & F3/AF3 & 5 & $120[112,128]$ & $136[121,151]$ & -2.52 & 1.48 \\
\hline & & & $\mathrm{F} 4 / \mathrm{AF} 4$ & 5 & $118[110,126]$ & $136[122,150]$ & $-3.36^{*}$ & 1.73 \\
\hline & \multirow[t]{4}{*}{ P2 } & \multirow[t]{2}{*}{ Amplitude } & F3/AF3 & 5 & $0.07[-1.7,1.8]$ & $-0.08[-1.6,1.5]$ & 0.62 & 0.09 \\
\hline & & & F4/AF4 & 5 & $0.54[-2.0,3.1]$ & $-0.09[-1.6,1.5]$ & 1.14 & 0.3 \\
\hline & & \multirow[t]{2}{*}{ Latency } & F3/AF3 & 5 & $158[133,183]$ & $167[143,191]$ & $-3.2 *$ & 0.4 \\
\hline & & & $\mathrm{F} 4 / \mathrm{AF} 4$ & 5 & $167[147,187]$ & $175[159,191]$ & $-3.16^{*}$ & 0.44 \\
\hline & \multirow[t]{4}{*}{$\mathrm{N} 2$} & \multirow[t]{2}{*}{ Amplitude } & F3/AF3 & 18 & $-8.89[-10.4,-7.4]$ & $-7.93[-9.6,-6.3]$ & $-3.19 * *$ & 0.3 \\
\hline & & & $\mathrm{F} 4 / \mathrm{AF} 4$ & 18 & $-8.29[-9.6,-7.0]$ & $-7.88[-9.1,-6.6]$ & -1.34 & 0.15 \\
\hline & & \multirow[t]{2}{*}{ Latency } & $\mathrm{F} 3 / \mathrm{AF} 3$ & 18 & $247[238,256]$ & $257[247,267]$ & $-5.05 * * *$ & 0.5 \\
\hline & & & F4/AF4 & 18 & $248[234,262]$ & $259[246,272]$ & -1.48 & 0.39 \\
\hline \multirow[t]{16}{*}{ Deviant } & \multirow[t]{4}{*}{$\mathrm{P} 1$} & \multirow[t]{2}{*}{ Amplitude } & $\mathrm{F} 3 / \mathrm{AF} 3$ & 18 & $3.09[1.5,4.7]$ & $3.07[1.4,4.8]$ & $-0.3^{\wedge}$ & 0.01 \\
\hline & & & $\mathrm{F} 4 / \mathrm{AF} 4$ & 18 & $3.07[1.3,4.8]$ & $2.93[1.1,4.8]$ & $-0.26^{\wedge}$ & 0.04 \\
\hline & & \multirow[t]{2}{*}{ Latency } & F3/AF3 & 18 & $94[85,103]$ & $101[92,110]$ & $-3.55^{* *}$ & 0.39 \\
\hline & & & F4/AF4 & 18 & $93[85,101]$ & $103[95,111]$ & $-3.54^{\wedge * * *}$ & 0.58 \\
\hline & \multirow[t]{4}{*}{ N1 } & \multirow[t]{2}{*}{ Amplitude } & $\mathrm{F} 3 / \mathrm{AF} 3$ & 4 & $-7.24[-7.9,-6.6]$ & $-6.83[-9.0,-4.7]$ & -0.5 & 0.36 \\
\hline & & & $\mathrm{F} 4 / \mathrm{AF} 4$ & 4 & $-5.90[-7.4,-4.4]$ & $-6.89[-8.6,-5.2]$ & $4.08^{*}$ & 0.78 \\
\hline & & \multirow[t]{2}{*}{ Latency } & $\mathrm{F} 3 / \mathrm{AF} 3$ & 4 & $115[97,133]$ & $127[110,144]$ & $-5.2 *$ & 0.82 \\
\hline & & & F4/AF4 & 4 & $125[102,148]$ & $132[110,154]$ & $-15.72 * * *$ & 0.41 \\
\hline & \multirow[t]{4}{*}{ P2 } & \multirow[t]{2}{*}{ Amplitude } & $\mathrm{F} 3 / \mathrm{AF} 3$ & 4 & $-1.74[-3.5,-0.0]$ & $-2.39[-4.0,-0.8]$ & 0.71 & 0.48 \\
\hline & & & F4/AF4 & 4 & $-2.02[-3.1,-1.0]$ & $-2.21[-4.7,0.3]$ & 0.17 & 0.13 \\
\hline & & \multirow[t]{2}{*}{ Latency } & $\mathrm{F} 3 / \mathrm{AF} 3$ & 4 & $165[132,198]$ & $186[156,216]$ & -1.85 & 0.81 \\
\hline & & & F4/AF4 & 4 & $174[143,205]$ & $180[153,207]$ & -1.38 & 0.26 \\
\hline & \multirow[t]{4}{*}{$\mathrm{N} 2$} & Amplitude & $\mathrm{F} 3 / \mathrm{AF} 3$ & 18 & $-11.51[-13.8,-9.2]$ & $-10.00[-12.4,-7.6]$ & $-2.62 *$ & 0.31 \\
\hline & & & F4/AF4 & 18 & $-10.93[-13.0,-8.9]$ & $-10.68[-12.8,-8.6]$ & -0.43 & 0.06 \\
\hline & & Latency & $\mathrm{F} 3 / \mathrm{AF} 3$ & 18 & $230[213,247]$ & $236[217,255]$ & -1.9 & 0.17 \\
\hline & & & F4/AF4 & 18 & $236[221,251]$ & $238[220,256]$ & -0.26 & 0.05 \\
\hline
\end{tabular}


Table 5 (on next page)

Neuroscan versus EPOC EEG system P3 and MMN peak comparisons

Descriptive ( $\mathrm{n}, \mathrm{M}$ [lower, upper 95\% confidence intervals]) and inferential (t or Wilcoxon Z and Cohen's d) statistics for peak amplitude ( $\mu \mathrm{V})$ and latency (ms) measures produced by the Neuroscan and EPOC systems at F3/AF3 and F4/AF4 for the P3 ERP peak (to deviant tones in the active condition) and the MMN ERP component (the difference between ERPs to standard and deviant tones in the passive condition). Note: ^ Wilcoxon $\mathrm{Z}, * \mathrm{p}<.05, * * p<.01, * * * \mathrm{p}<$ .001 


\begin{tabular}{llllllll}
\hline \multirow{2}{*}{ ERP } & \multirow{2}{*}{ Measure } & Site & $\mathrm{n}$ & Neuroscan & EPOC & stat. & $\mathrm{d}$ \\
\hline \multirow{2}{*}{ P3 } & Amplitude & F3/AF3 & 18 & $-2.30[-4.2,-0.4]$ & $-2.46[-4.1,-0.8]$ & 0.45 & 0.04 \\
& & F4/AF4 & 18 & $-2.51[-4.5,-0.6]$ & $-2.46[-4.3,-0.6]$ & -0.11 & 0.01 \\
& \multirow{2}{*}{ Latency } & F3/AF3 & 18 & $336[320,352]$ & $351[333,369]$ & $-2.91^{* *}$ & 0.44 \\
& & F4/AF4 & 18 & $338[322,354]$ & $353[337,369]$ & $-3.53 * *$ & 0.45 \\
\hline \multirow{2}{*}{ MMN } & \multirow{2}{*}{ Amplitude } & F3/AF3 & 18 & $-4.21[-5.6,-2.9]$ & $-4.54[-5.8,-3.3]$ & 0.56 & 0.12 \\
& & F4/AF4 & 18 & $-4.69[-6.1,-3.3]$ & $-4.95[-6.2,-3.7]$ & 0.42 & 0.09 \\
& \multirow{2}{*}{ Latency } & F3/AF3 & 18 & $193[179,207]$ & $198[181,215]$ & -0.73 & 0.17 \\
& & F4/AF4 & 18 & $191[176,206]$ & $201[185,217]$ & -1.19 & 0.29 \\
\hline
\end{tabular}


1

Schematic diagram of simultaneous Neuroscan (in grey) and EPOC (in black) setup, including infrared transmission for EPOC event markers

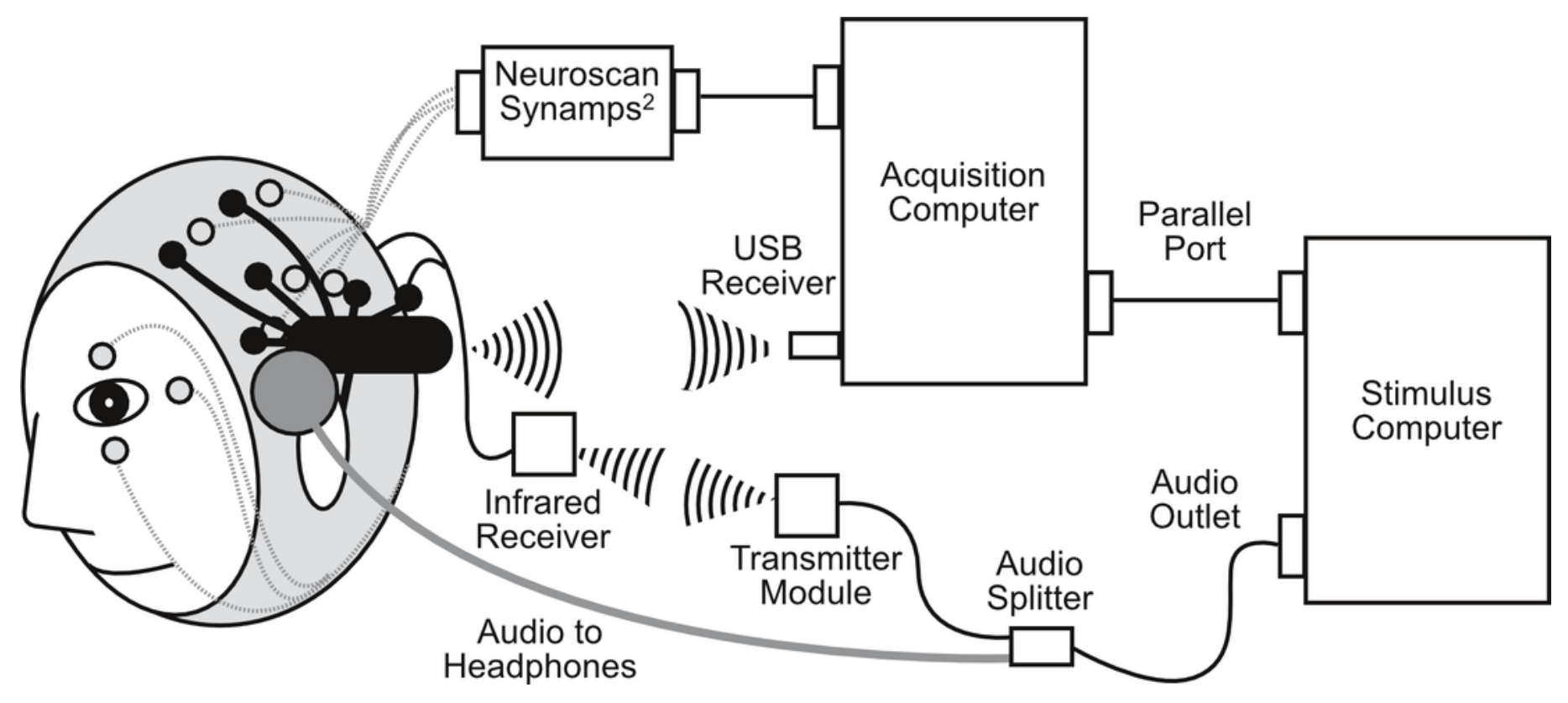


2

Schematic diagram depicting the placement of EEG electrodes for Neuroscan (blue targets) and EPOC (orange crosses) systems.

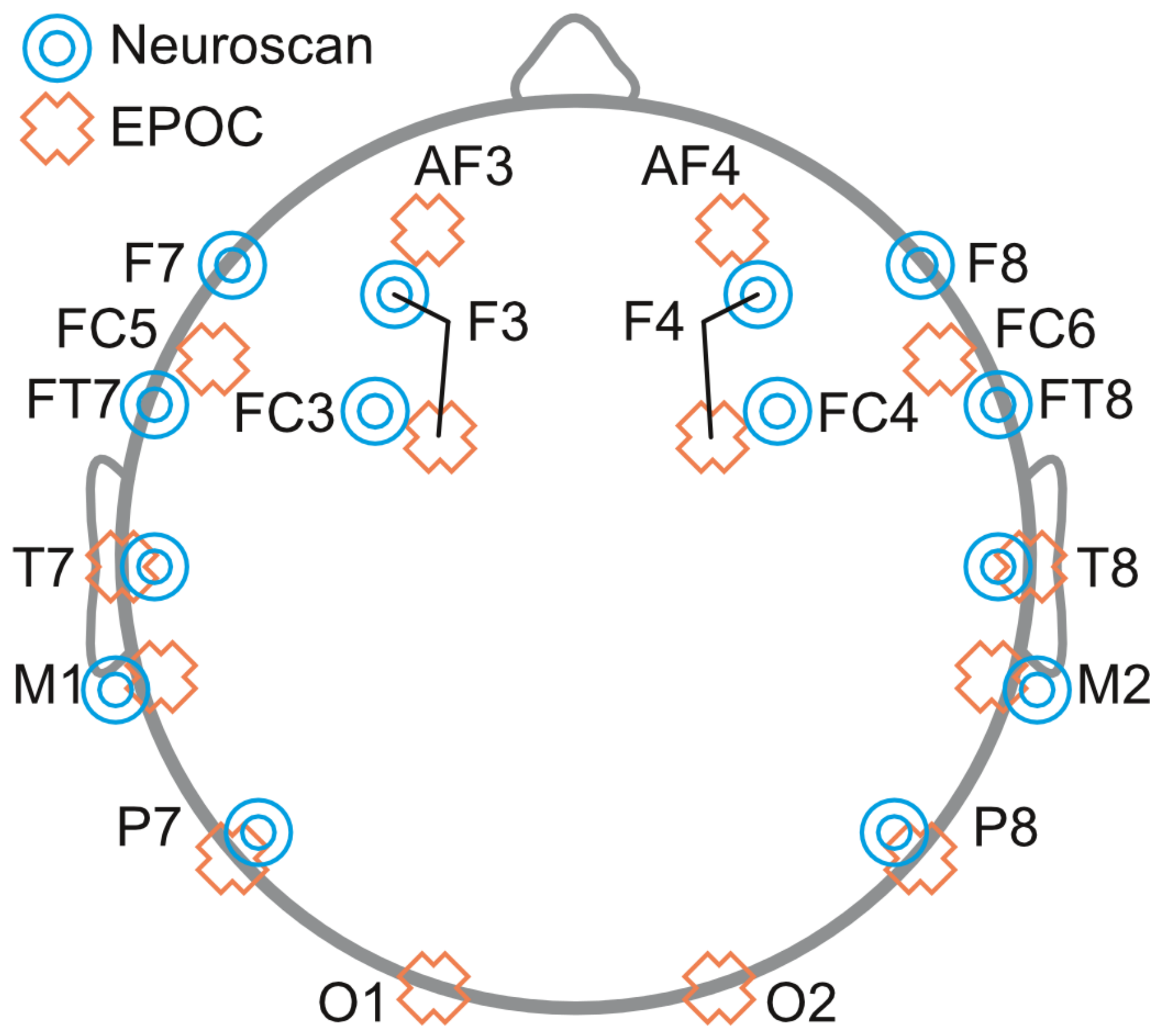




\section{3}

Event-related potential (ERP) waveforms for Neuroscan and EPOC by tone, hemisphere, and condition

All graphs display the group average ERP waveforms for the passive (ignore tones) and active (count deviant tones) listening conditions. Data collected with Neuroscan and EPOC are presented in the left and right columns respectively, ERPs to the standard (low) tones are presented in panels $A, B, E, \& F$, and ERPs to the deviant (high) tones are presented in panels $C, D, G, \& H$. The upper four panels depicted ERPs from the left-hemisphere (Neuroscan $=F 3$ : $A \& C ; E P O C=A F 3: B \& D$ ) and the lower four panels depicted ERPs from the righthemisphere (Neuroscan $=F 4: E \& G ; E P O C=A F 4: F \& H)$. 


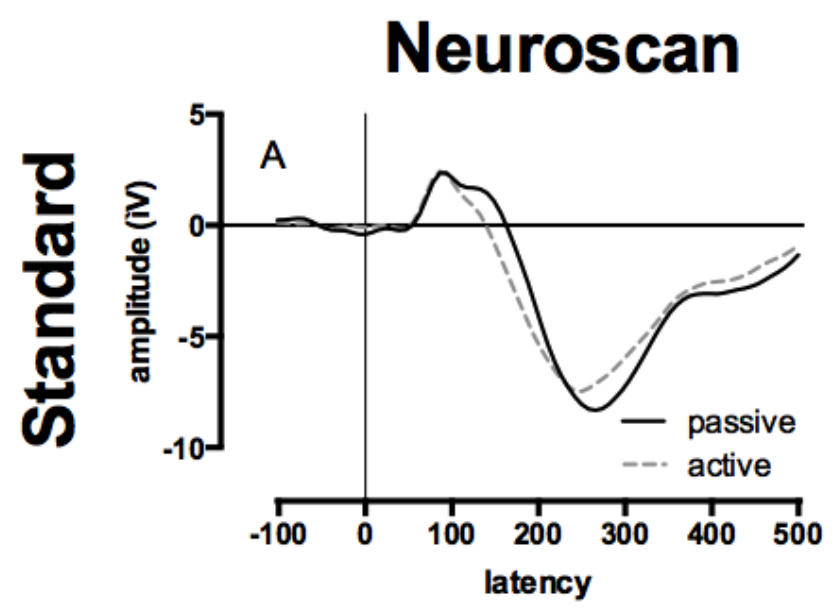

EPOC
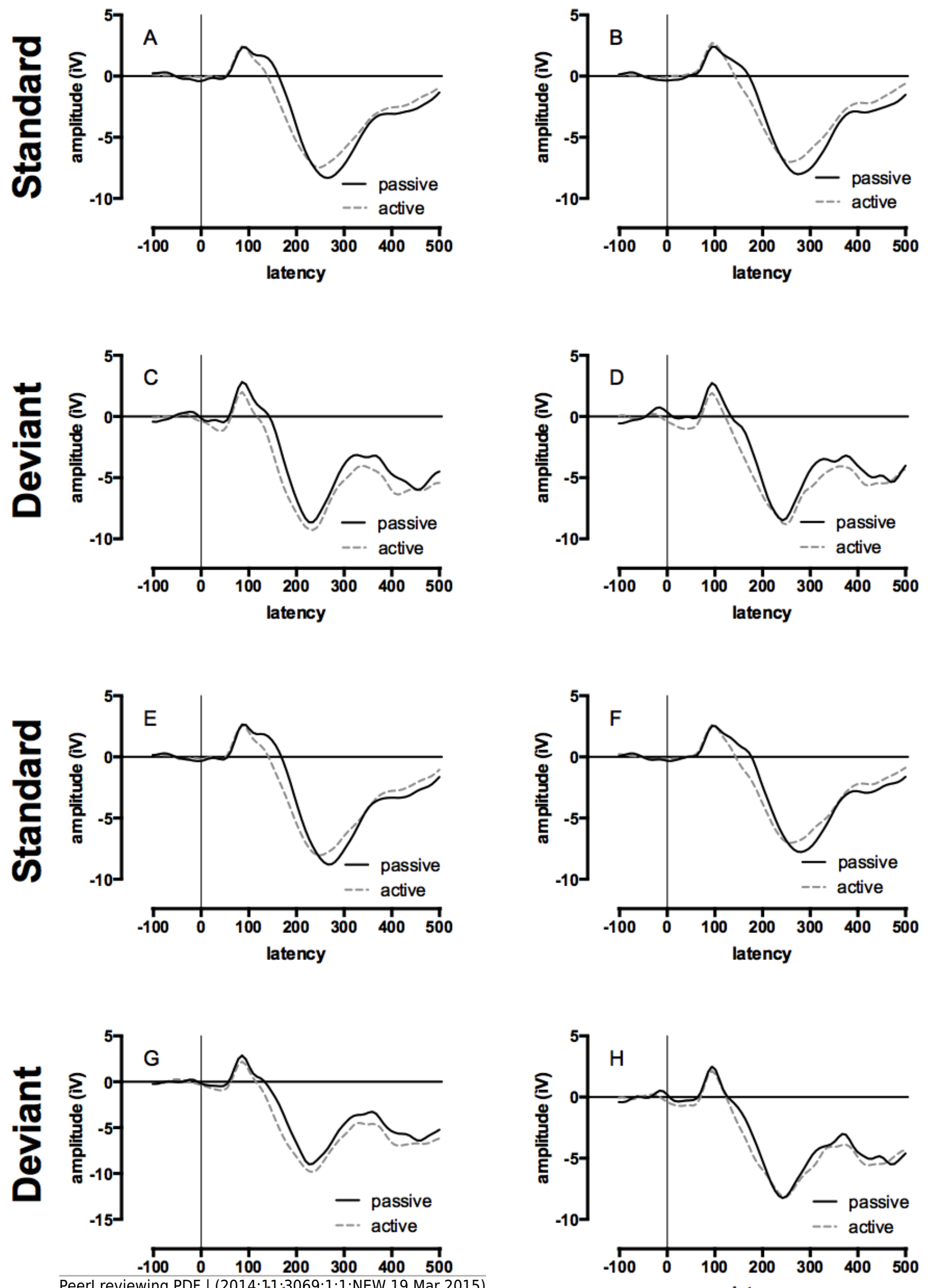

PeerJ reviewing PDF | (2014:1]:30669:1:1:NEW 19 Mar 2015)

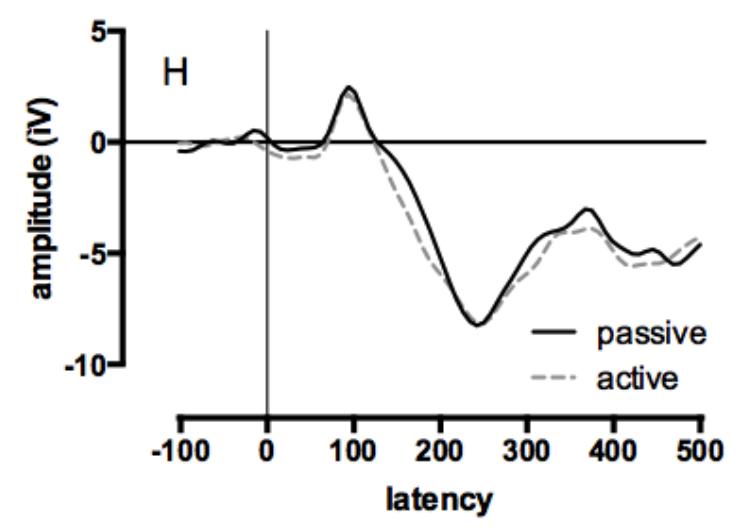




\section{4}

Event-related potential (ERP) waveforms for Neuroscan and EPOC by tone and hemisphere for the passive condition (ignore tones)

Data collected with the Neuroscan and EPOC are presented in the left and right columns respectively, ERPs to the standard (low) and deviant (high) tones are presented in panels $A$, $B, E, \& F$, and the difference between these waveforms (i.e., the mismatch negativity responses) are presented in panels $C, D, G, \& H$. The upper four panels depicted ERPs from the left-hemisphere (Neuroscan $=F 3: A \& C ; E P O C=A F 3: B \& D$ ) and the lower four panels depicted ERPs from the right-hemisphere (Neuroscan = F4: E \& G; EPOC = AF4: F\&H). 
Neuroscan
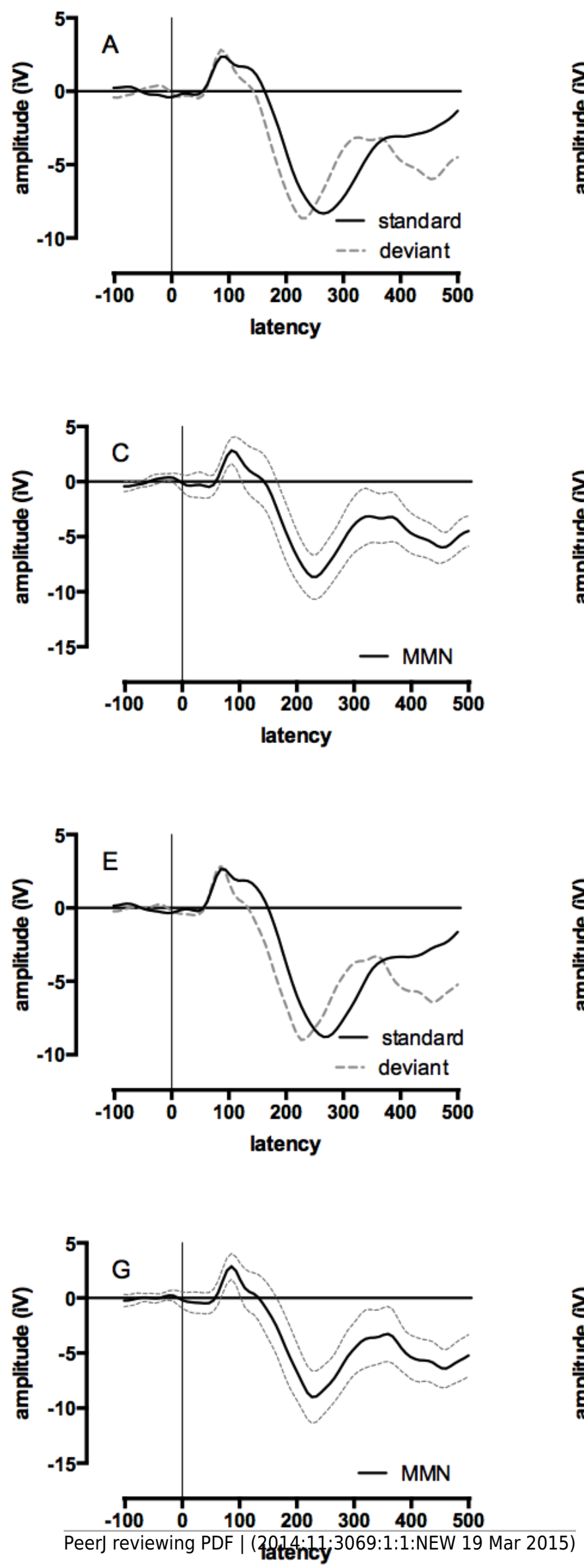

EPOC
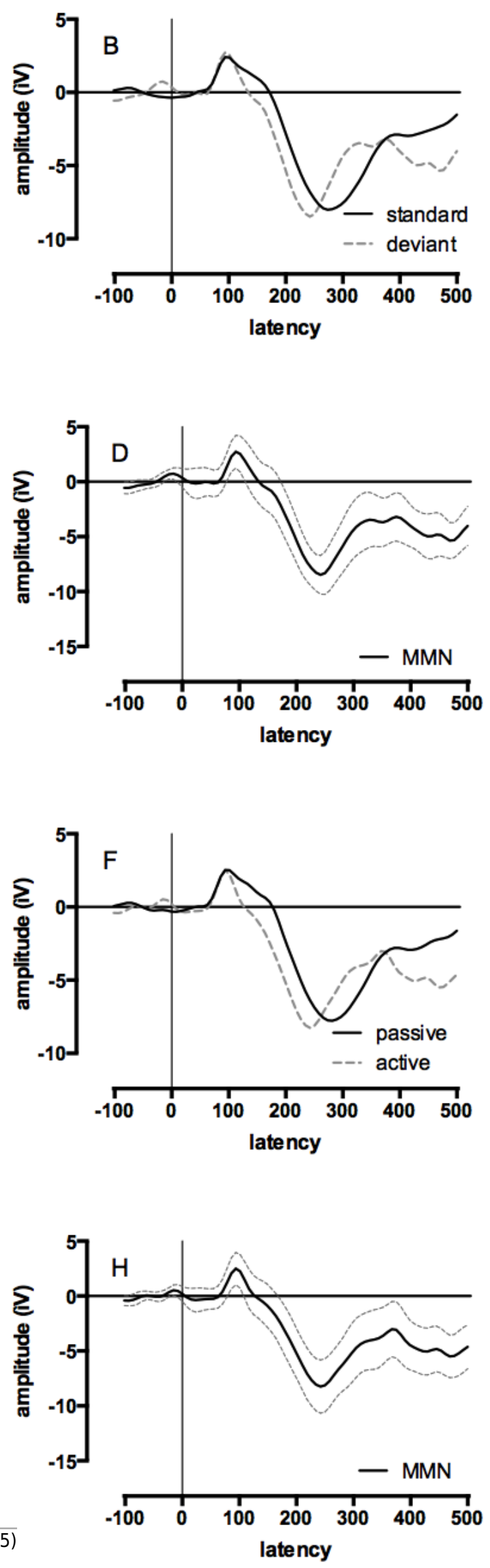